\title{
EFFECTS OF HARMALINE ON MEMBRANE EXCITABILITY AND ATPase ACTIVITY OF THE CRAYFISH GIANT AXON
}

\author{
Hitoshi ISHIDA, Masashi SASA, Shuji TAKAORI and \\ Hajime ISHIDA* \\ Department of Pharmacology, Faculty of Medicine, Kyoto University, Sakyo-ku, Kyoto 606 , \\ and "Department of Pharmacology. School of Dentistry. \\ University of Tokushima, Tokushima 770, Japan
}

Accepted June 2, 1981

\begin{abstract}
Effects of harmaline on excitability of crayfish giant axon in relation to effects on $\mathrm{Na}, \mathrm{K}$-ATPase activity were investigated and the findings were compared with relative data on ouabain. Exposure of the axon to harmaline in doses over $0.5 \mathrm{mM}$ resulted in a dose-dependent reduction of the action potential. Harmaline of $2.5 \mathrm{mM}$ produced a complete blockade of the action potential with a slight decrease in the resting membrane potential ( $5.7 \mathrm{mV}$ ), but no alterations of $\mathrm{Na}, \mathrm{K}$-ATPase activity. In contrast, ouabain ( $5 \mathrm{mM}$ ) produced a more pronounced decrease in the resting membrane potential $(10.6 \mathrm{mV})$ and also a partial reduction in the action potential, while a significant decrease in Na,K-ATPase activity was obtained. Increasing the membrane potential to the initial level resulted in a partial recovery $(46 \%)$ of the rising rate $(d V / d t)$ of action potential. The $\mathrm{dV} / \mathrm{dt}$ was exponentially decreased when the resting potential was reduced with application of $\mathrm{KCl}$ solution over $8 \mathrm{mV}$. These results suggest that harmaline externally applied produces a decrease in sodium conductance without affecting Na.K-ATPase activity, while ouabain inhibits Na,KATPase activity and, to lesser extent, decreases in sodium conductance.
\end{abstract}

Harmaline has a variety of effects both in in vitro and in vivo experiments. Rojas et al. (1) have demonstrated that the drug reversibly suppresses the action potential of the squid giant axon without affecting the resting membrane potential. The ability of harmaline to abolish inhibitory synaptic transmission has been investigated in the stretch receptor of the crayfish (2). The drug produced a dual action in the rat atrial contractile fibers with respect to the dose, that is an initial increase in the amplitude of the action potential and then a decrease with an increment of the dose (3). The inhibition by harmaline of $\mathrm{Na}, \mathrm{K}$-ATPase activity has been reported in the case of the squid axon and rat brain (4).
However, there is still a paucity of information concerning the mode of action of harmaline on the membrane excitability. In the present study, we investigated quantitatively the effects of harmaline on the excitability of the crayfish giant axon in relation to the effect on Na,K-ATPase activity and compared the findings with relative data on ouabain, a competitive inhibitor of Na,K-ATPase.

\section{MATERIALS AND METHODS}

Electrophysiological study: The circumoesophageal giant axon of crayfish, Procambarus clarkii, was desheathed and mounted in a chamber (about $5 \mathrm{ml}$ in volume) into which physiological solution was con- 
tinuously perfused at the rate of $5 \mathrm{ml} / \mathrm{min}$. The axon, with a diameter of 50-100 $\mu$. was impaled with two glass capillary microelectrodes filled with $3 \mathrm{M} \mathrm{KCl}$. One was used to deliver the stimulating current and hyperpolarizing current and the other to record the membrane and action potentials. The stimulus, composed of a square wave pulse of 30 msec duration. was applied every $1.0 \mathrm{sec}$. Resting membrane potential was continuously recorded on a rectigram (Nihon Konden. PMP-3302). Action potential and its rising rate $(\mathrm{dV} / \mathrm{dt})$ were displayed on an oscilloscope (Nihon Kohden, VC-7) after amplification. The time constant of an RC circuit was 22 usec for electrical differentiation.

Composition of the physiological solution was as follows in mM: $\mathrm{NaCl} 250, \mathrm{KCl} 5.4$, $\mathrm{CaCl}_{2}$ 13.5, $\mathrm{MgCl}_{2}$ 2.6. $\mathrm{NaHCO}_{3}$ 2.3. The solution was bubbled with a mixture of $95 \%$ $\mathrm{O}_{2}$ and $5 \% \mathrm{CO}_{2}$ for $30 \mathrm{~min}$, and the final $\mathrm{pH}$ of the solution with or without the drugs was adjusted to 7.4 by adding either $1 \mathrm{~N} \mathrm{HCl}$ or $1 \mathrm{~N} \mathrm{NaOH}$. Harmaline hydrochloride (Sigma) and ouabain (Merck) were dissolved in physiological solution and were continuously perfused into the bath. Other details of the experiments were as outlined in our previous paper (5).

Biochemical study: One group of 10 desheathed axons (wet weight of 10 axons: approx. $17 \mathrm{mg}$ ), after continuous perfusion with physiological solution containing harmaline or ouabain for $30 \mathrm{~min}$, in a similar manner to the electrophysiological study. were washed twice for 5 min with ice-cold $0.25 \mathrm{M}$ sucrose containing $10 \mathrm{mM}$ Tris-EDTA and

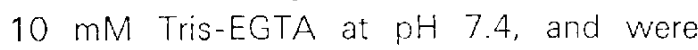
homogenized in $1.0 \mathrm{ml}$ of the abovementioned sucrose by a glass homogenizer with a Tefion pestle. Total ATPase activity was assayed at $37^{\circ} \mathrm{C}$ in a final volume of $2.0 \mathrm{ml}$ containing $100 \mathrm{mM} \mathrm{NaCl}, 20 \mathrm{mM} \mathrm{KCl}$, $3 \mathrm{mM} \mathrm{MgCl}_{2}, 3 \mathrm{mM}$ Tris-ATP and $20 \mathrm{mM}$
Tris- $\mathrm{HCl}$ (pH 7.4). After a 10-min preincubation of samples containing 70-100 $/ \mathrm{g}$ proteins, the reaction was started with the addition of ATP. was allowed to continue for $30 \mathrm{~min}$, then terminated by adding $0.2 \mathrm{ml}$ of $100 \%$ trichloroacetic acid. The samples were centrifuged at $8,000 \times \mathrm{g}$ for $10 \mathrm{~min}$. Since harmaline interfered with the analysis, two extractions with $2.5 \mathrm{ml}$ of isobutanol were performed to remove the drug from the aqueous solution. according to the method of Canessa et al. (4). Inorganic phosphate (Pi) in the supernatant fluid was measured by the method of Fiske and Subbarow (6). Mg-ATPase activity was assayed in the absence of $\mathrm{Na}^{+}$and $\mathrm{K}^{+}$, and $\mathrm{Na}, \mathrm{K}$-ATPase activity was calculated as the total ATPase activity minus Mg-ATPase activity. These activities were calculated as $/$ moles $\mathrm{Pi} / \mathrm{mg}$ protein/hr. The method of Lowry et al. (7) was used to determine the protein concentration. Statistical significance of the data was determined by Student's $t$-test.

\section{RESULTS}

Electrophysiological study: The mean resting membrane potential, amplitude of action potential and $\mathrm{dV} / \mathrm{dt}$ in 45 axons were $-84.9 \mathrm{mV}, 101.3 \mathrm{mV}$ and $663 \mathrm{~V} / \mathrm{sec}$, respectively. When $0.25-2.5 \mathrm{mM}$ of harmaline was added to the bath for $30 \mathrm{~min}$, the amplitude and $\mathrm{dV} / \mathrm{dt}$ of the action potential were dosedependently reduced (Table 1). Fig. 1A demonstrates that exposure of the axon to $2.5 \mathrm{mM}$ harmaline resulted in a complete blockade of the action potential generation with a slight depolarization of the resting membrane potential. The mean depolarization of the membrane potential was $5.7 \mathrm{mV}$ with a dose of $2.5 \mathrm{mM}$. When the axon was treated with $2.5 \mathrm{mM}$ harmaline for $30 \mathrm{~min}$ and then washed with physiological solution for $60 \mathrm{~min}$, the $\mathrm{dV} / \mathrm{dt}$ of the action potential was partially restored to $273 \mathrm{~V} / \mathrm{sec}$. The action potential threshold remained 
HARMALINE AND CRAYFISH GIANT AXON

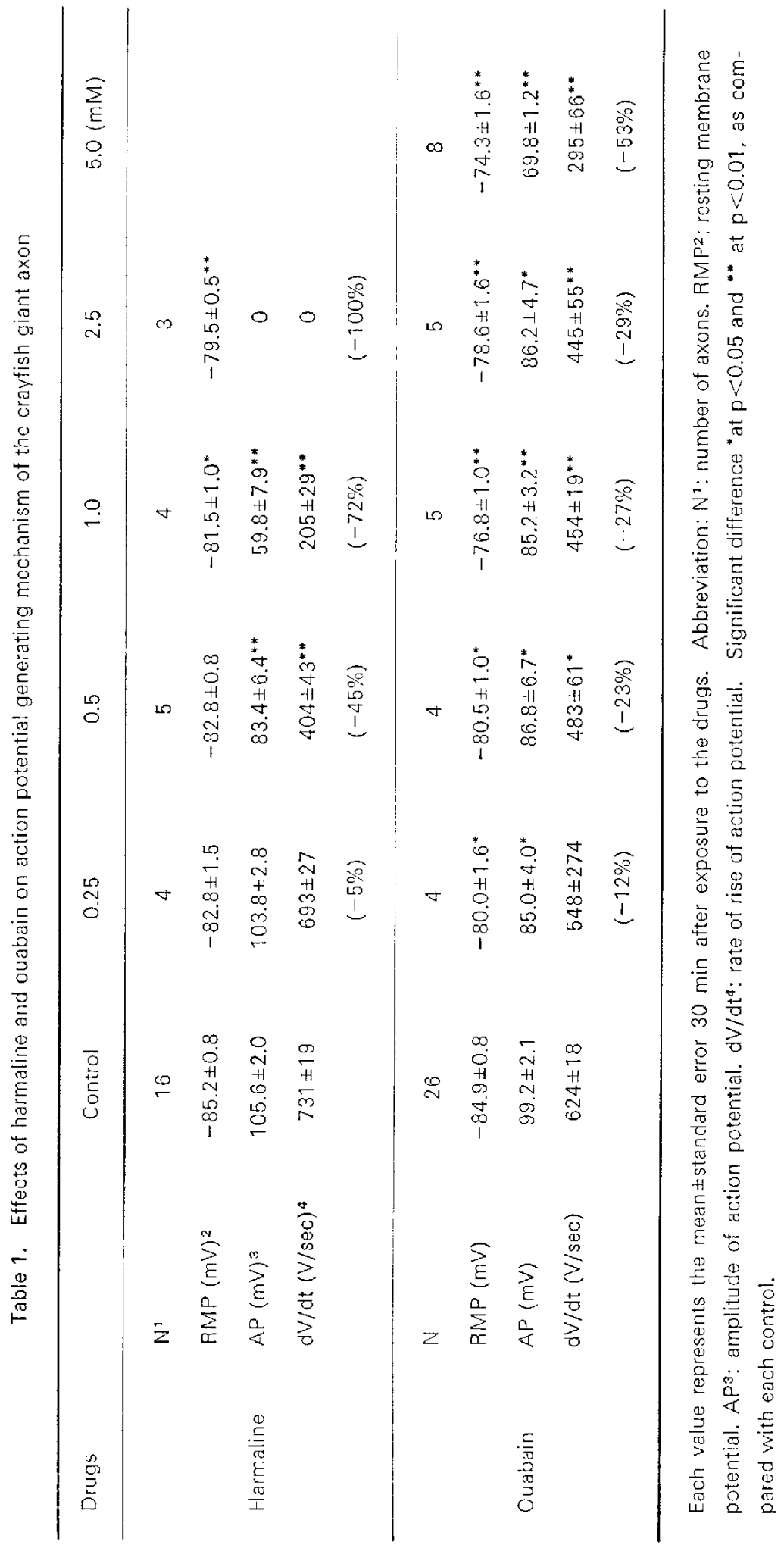




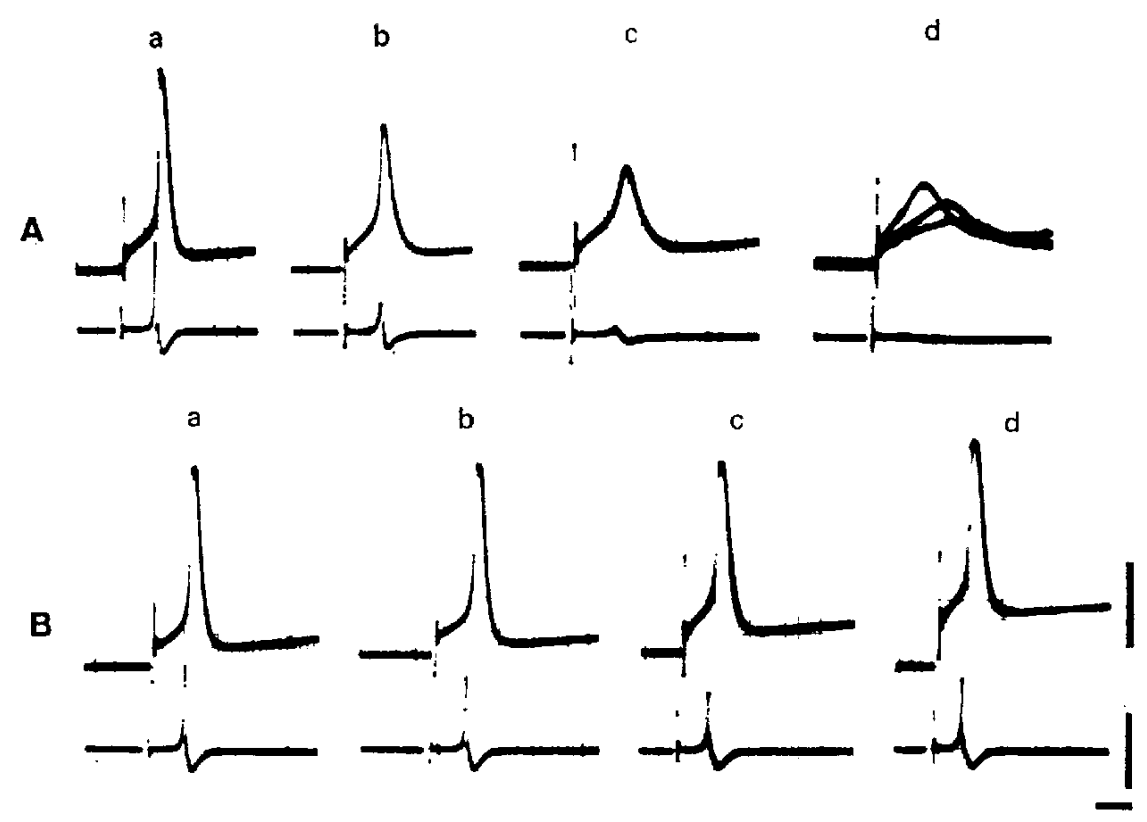

Fig. 1. Effects of $2.5 \mathrm{mM}$ harmaline (A) and $5.0 \mathrm{mM}$ ouabain (B) on the action potential of crayfish giant axon. Upper traces in each figure are the action potential, and lower traces the $\mathrm{dV} / \mathrm{dt}$ of the potentials. Aa and $\mathrm{Ba}:$ before. $\mathrm{Ab}: 10 \mathrm{~min}$. Ac and $\mathrm{Bb}: 20 \mathrm{~min}$. Ad and Bc: 30 min after the drug application. Bd: when the membrane potential was increased to the initial level by passing negative current. Calibration: $50 \mathrm{mV}$ for the action potential and $500 \mathrm{~V} / \mathrm{sec}$ for the $\mathrm{dV} / \mathrm{dt}$. Time scale: $1.0 \mathrm{msec}$.

Table 2. Effects of ouabain $(5.0 \mathrm{mM})$ on action potential generating mechanism of crayfish giant axon when the resting membrane potential was increased to the initial level

\begin{tabular}{lccc}
\hline & Control & $\begin{array}{c}\text { Ouabain } \\
(30 \mathrm{~min})\end{array}$ & $\begin{array}{c}\text { Increase } \\
\text { of RMP }\end{array}$ \\
$\operatorname{RMP}(\mathrm{mV})^{1}$ & $-82.7 \pm 1.3$ & $-72.7 \pm 1.8$ & $-82.7 \pm 1.3$ \\
$\operatorname{AP}(\mathrm{mV})^{2}$ & $96.7 \pm 1.8$ & $80.7 \pm 4.7^{*}$ & $87.3 \pm 3.7$ \\
& & $(-16 \%)$ & $(-10 \%)$ \\
$\mathrm{dV} / \mathrm{dt}(\mathrm{V} / \mathrm{sec})^{3}$ & $644 \pm 27$ & $394 \pm 55^{*}$ & $530 \pm 30^{*}$ \\
& & $(-39 \%)$ & $(-18 \%)$ \\
\hline
\end{tabular}

Each value represents the meantstandard error $(n=3)$. Abbroviation: RMP1: resting mombrane potential. $\mathrm{AP}^{2}$ : amplitude of action potential. $\mathrm{dV}^{\mathrm{d}} \mathrm{dt}^{3}$ : rate of rise of action potential. Significant difference "at $P<0.05$. as compared with each control.

unaffected with doses up to $1.0 \mathrm{mM}$ harmaline.

The potency of ouabain on the action potential generation was considerably less than that obtained with harmaline, as shown in Table 1. A $53 \%$ inhibition of the $\mathrm{dV} / \mathrm{dt}$ was observed $30 \mathrm{~min}$ after treatment of the axon with the highest dose of ouabain used
(5 $\mathrm{mM}$ ) concomitantly with a decrease in the resting membrane potential by $10.6 \mathrm{mV}$. The action potential threshold was not altered with doses up to $5 \mathrm{mM}$. Figure $1 \mathrm{~B}$ demonstrates that the application of $5 \mathrm{mM}$ ouabain to the bath for $30 \mathrm{~min}$ resulted in a decrease in amplitude and $\mathrm{dV} / \mathrm{dt}$ of the action potential. At this time, increasing the membrane 
potential to the initial level by passing a negative current resulted in a partial recovery of the amplitude and $d V / d t$ (compare $d$ with a in Fig. 1B). The mean $\mathrm{dV} / \mathrm{dt}$ of the action potential $(n=3)$ with $5 \mathrm{mM}$ ouabain in 30 min was reduced by $18 \%$ and $39 \%$ in the presence and absence of hyperpolarizing current, respectively (Table 2).

The relationship between the resting membrane potential and the $\mathrm{dV} / \mathrm{dt}$ of action potential was examined by depolarizing the membrane with addition of a small amount of $3 \mathrm{M} \mathrm{KCl}$ solution to the bath. Since adding $50 \mu$ of $\mathrm{KCl}$ solution resulted in a rapid and gradual membrane depolarization and complete blockade of the action potential within 3-5 min, the resting membrane potential and $\mathrm{dV} / \mathrm{dt}$ were continuously recorded. The reduction of $\mathrm{dV} / \mathrm{dt}$

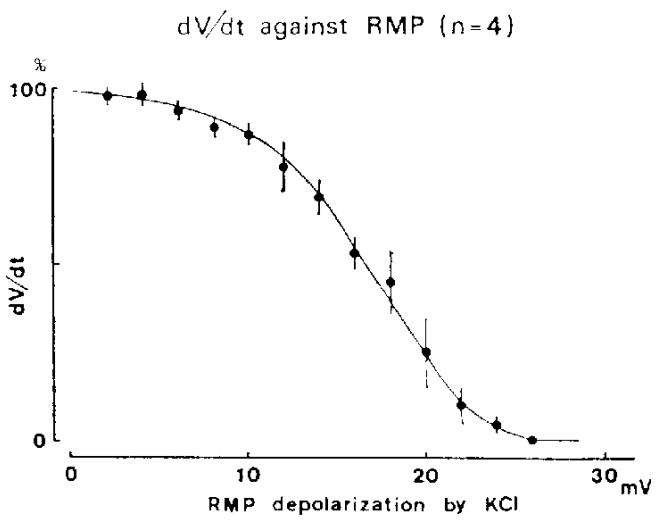

Fig. 2. Relationship between the resting membrane potential (RMP) and $\mathrm{dV} / \mathrm{dt}$ of the action potential. Decrease of the RMP was obtained with addition of $\mathrm{KCl}$ solution. Vertical bar on each point indicates standard error $(n=4)$. was negligible during the depolarization of the membrane up to $5 \mathrm{mV}$ (Fig. 2). When the membrane was depolarized more than $8 \mathrm{mV}$. the $\mathrm{dV} / \mathrm{dt}$ was exponentially declined and finally reduced to zero with $26 \mathrm{mV}$ depolarization.

Biochemical study: Na,K-ATPase and Mg-ATPase activities were assayed in the axon exposed to harmaline and ouabain under similar conditions to those in the electrophysiological study. Na.K-ATPase activity was significantly $(P<0.01)$ reduced with $5 \mathrm{mM}$ ouabain in $30 \mathrm{~min}$, but remained unaltered with $2.5 \mathrm{mM}$ harmaline (Table 3 ). Mg-ATPase activity was not affected with doses of $2.5 \mathrm{mM}$ harmaline and $5 \mathrm{mM}$ ouabain.

\section{DISCUSSION}

Harmaline in a dose of $2.5 \mathrm{mM}$ completely blocked the action potential generating mechanism with a slight decrease (less than $6 \mathrm{mV}$ ) in the resting membrane potential. Since the decrease in the resting membrane potential up to $6 \mathrm{mV}$ did not affect the action potential as demonstrated in Fig. 2, the blockade of the action potential produced by harmaline is not due to the decrease in the resting membrane potential. Furthermore, $\mathrm{Na}, \mathrm{K}$-ATPase activity remained unaffected with harmaline under similar conditions as in the electrophysiological study. Therefore, a decrease in the resting membrane potential with harmaline is considered to be at least partly due to a decrease in the resting membrane potassium permeability. Our findings

Table 3. Effects of harmaline and ouabain on $\mathrm{Na}, \mathrm{K}$ - and $\mathrm{Mg}$-ATPase activities in the crayfish giant axon

\begin{tabular}{lccc} 
& Control & Harmaline & Ouabain \\
& & $2.5 \mathrm{mM}$ & $5.0 \mathrm{mM}$ \\
Na.K-ATPase & $0.76 \pm 0.01$ & $-0.75 \pm 0.01$ & $0.63 \pm 0.01^{*}$ \\
Mg-ATPase & $0.33 \pm 0.04$ & $0.32 \pm 0.03$ & $0.30 \pm 0.04$ \\
\hline
\end{tabular}

Each value ( $\mu$ moles $\mathrm{Pi} / \mathrm{mg}$ protein/hr) represents the meantstandard error of 5 determinations. Significant difference "at $P<0.01$, as compared with the control. 
that harmaline blocked the action potential of the crayfish giant axon paralle! those obtained in the case of squid axon (1) and crayfish stretch receptor (2). Unlike the findings in the squid retinal axon and rat brain reported by Canessa et al. (4), our results failed to demonstrate the inhibition by harmaline of Na.K-ATPase activity. In the experiment of Canessa et al. (4), the results were obtained by adding harmaline to homogenates of the preparation. Therefore the lack of effects of harmaline on the enzyme activity in our experiment suggests that the drug may not enter the membrane at the site of $\mathrm{Na}, \mathrm{K}$-ATPase or not act on the enzyme combined with the membrane in the crayfish axon. In addition, the possibility cannot completely be excluded that harmaline may have been removed from its site and bound with ATPase during 60 min of the determination procedures. Nevertheless, since the action potential remained partially inhibited $60 \mathrm{~min}$ after washing the preparation, it is suggested that the blockade of the action potential by harmaline is not related to the ATPase inhibition.

In contrast to the action of harmaline. exposure of the axon to $5 \mathrm{mM}$ ouabain produced a decrease in the action potential concomitant with considerable depolarization (more than $10 \mathrm{mV}$ ) of the resting membrane potential and a reduction of $\mathrm{Na}, \mathrm{K}$-ATPase activity. It has been reported that ouabain produces a decrease in Na, KATPase activity, resting membrane potential and resting membrane resistance in the crayfish giant axon $(8,9)$ and frog muscle fibers (10). Lieberman and Nosek (11) concluded that the membrane depolarization in the crayfish axon produced by ouabain was to a great extent due to the inhibition of an electrogenic $\mathrm{Na}-\mathrm{K}$ transport current, and in part due to an increase in sodium permeability in the resting state, and that a reduction of the resting membrane resistance was due to an increase in chloride conductance, the net effect resulting in a decrease in the resting membrane potential. In our results, recovery of the action potential with an increase in the resting membrane potential to the initial level by passing a negative current was less than $60 \%$ of the control. It is suggested. therefore, that the reduction of the action potential produced by ouabain is at least due to a decrease in sodium conductance, an inhibition of Na,K-ATPase activity and changes of the resting membrane conductance.

\section{REFERENCES}

1) Rojas, A., Herrera, J., Delpiano, M. and Riobo, F.: Effects of harmalire on visual system of the rat. Vision Res., Supp. 3, 437-445 (1971)

2) Sokolove, P.G. and Roth, S.H.: Effect of harmaline on the crayfish stretch receptor: Blockade at a GABA-mediated inhibitory synapse. Neuropharmacology 17, 729-735 (1978)

3) Carpentier, R. and Narvarte, J.: The effect of harmaline on membrane potentials of rat atrial contractile fibers. Europ. J. Pharmacol. 32, 313-323 (1975)

4) Canessa, M., Jaimovich, E. and de la Fuente, M.: Harmaline: A competitive inhibitor of $\mathrm{Na}$ ion in the $\left(\mathrm{Na}^{+}+\mathrm{K}^{+}\right)$-ATPase system. J. Membr. Biol. 13, 263-282 (1973)

5) Ishida, H., Sasa, M. and Takaori, S.: Local anesthetic activity of $\beta$-adrenergic blocking drugs in the crayfish giant axon. with reference to calcium ion. Japan. J. Pharmacol. 30, 607619 (1980)

6) Fiske, C.H. and Subbarow, Y.: The colorimetric determination of phosphorus. J. biol. Chem. $66,375-400$ (1925)

7) Lowry, O.H., Rosebrough, N.J., Farr, A.L. and Randall, R.J.: Protein measurement with the Folin phenol reagent. J. biol. Chem. 193, 265275 (1951)

8) Lieberman, E.M. and Lane, T.G.: The influence of cardioactive steroids, metabolic inhibitors, temperature and sodium on membrane conductance and potential of crayfish giant axon. Pliügers Arch. 366, 189-193 (1976)

9) Woods, W.T. and Lieberman, E.M.: The effect of papaverine on sodium-potassium adenosine triphosphatase and the ouabain sensitive electrical properties of crayfish neve. 
Neuroscience 1, 383-390 (1976)

10) Geduldig, D.: A ouabain-sensitive membrane conductance. J. Physiol. 194, 521-533 (1968)

11) Lieberman, E.M. and Nosek, T.M.: The influence of chloride on the ouabain-sensitive membrane potential and conductance of crayfish giant axons. Pflügers Arch. 366, 195-202 (1976) 